\title{
Classification of end-of-chapter questions in senior school chemistry textbooks used in Nigeria
}

\author{
Upahi, Johnson Enero ${ }^{1 *}$, Jimoh, Mutaheer ${ }^{2}$ \\ 1, 2Department of Science Education, University of Ilorin, Ilorin, Nigeria \\ For correspondence: johnsonenero@yahoo.com
}

\begin{abstract}
Textbooks are a prominent part of science teaching and learning. For science teachers and students, textbooks are the major source of information for planning and classroom practice. In addition to the content of textbooks, are end-ofchapter questions that should consolidate students learning and enhance their thinking processes. Therefore, this study adopted the framework of the revised Bloom's Taxonomy to classify and analyze end-of-chapter questions from three chemistry textbooks used in Nigeria. The results from this study indicated that majority $(76 \%)$ of the questions were at the lower order of (understand, remember, and apply), while $46 \%$ and $32 \%$ measure conceptual and procedural knowledge respectively. The results further revealed that the number of questions in the categories of evaluate and create differs significantly at, $F(5,1744)=5.61, \rho<.01$, from the other categories of the cognitive process skills. The following conclusions were drawn: understand and analyze categories recorded the highest number questions in the cognitive objectives; and there was no metacognitive questions. Implications for textbook authors and teachers were discussed.
\end{abstract}

Keywords: End-of-chapter questions, cognitive process skills, knowledge dimensions, chemistry textbooks

\section{Introduction}

The major source of information that is readily available to students for reading/studying, class-and homework is the science textbooks. In addition to the content of textbooks are in-chapter, end-ofchapter and bank of questions to consolidate students learning. These questions could be exercises in form of drills and repetition that only require students to apply an algorithm to arrive at the solution, or problems that are novel in nature and require students' conceptual understanding of what they have learnt in class and from the textbooks. The types of questions included in science (chemistry) textbooks could facilitate and enhance students' thinking processes and encourage them to work on their own.

Textbooks are a prominent part of teaching and learning. Researches in science education have shown that teachers rely, depend and use textbooks for planning and classroom practices (Britton, Woodward \& Binkley, 1995; Chambliss \& Calfee, 1998). Studies on science teachers' attitude and preference for science textbooks have also shown that while science teachers do not have consistent expectations from the normal texts, questions and other tasks is reported as one of the topmost criteria for textbook selection and their subsequent recommendation for students (Spiegel \& Wright, 1984; Cook \& Tulip, 1992).

\section{Conceptual Framework}

This research is conceptualized within the framework of taxonomy of cognitive domain provided by Bloom's (1956) and revised by Anderson and Krathwohl (2001). Bloom's taxonomy provides a foundation for developing learning objectives designed for learners to acquire knowledge. The taxonomy is designed to build content knowledge from basic foundation-remembering to more 
complex manipulation of content-creating. The taxonomy was originally designed as an assessment tool, even though; the taxonomy has provided a framework for learning, teaching and assessment that has been adopted in almost all environments where learning takes place. This may have influence its adoption in the design of science curricula and instructional systems in Nigeria.

Anderson and Krathwohl (2001) updated and redefined Bloom's original classification, which is the specific taxonomy employed in this research to classify end-of-chapter questions in chemistry textbooks. The revised taxonomy promotes two dimensions to guide the processes of stating learning objectives, and instruction that will lead to sharper, and more clearly defined assessments, which will consequently, provide a stronger connection of assessment to both the learning objectives and instruction. The two dimensional taxonomy of Anderson and Krathwohl (2001) place emphases on the need to assess higher order cognitive processes and metacognitive knowledge for all who are engaged in the field of assessment.

The two dimensions of knowledge and cognitive process as shown in (Table 1) have the noun and verb components that could be used in the classification of examination questions. The noun component provides the basis for the knowledge dimension, while the verb component forms the basis for the cognitive process dimension (Krathwohl, 2002).

Table 1: The Revised Taxonomy Table

\begin{tabular}{l} 
The Knowledge Dimension \\
\cline { 2 - 3 } Factual knowledge \\
Conceptual knowledge \\
Procedural knowledge \\
Metacognitive knowledge \\
Source. Adapted from "A Revision of Bloom's Taxonomy: An Overview" by D. R. Krathwohl, 2002, \\
Theory into Practice, 41 (4), p. 216.
\end{tabular}

In the original taxonomy, cognitive processes assume a hierarchical order that increases from left to right (as in Table 1). In the same vein, the category of the knowledge dimension also follows a continuum from factual knowledge through to metacognitive. Like the original, the revised taxonomy assumed a hierarchical structure in the sense that the six categories of the cognitive process dimension differs from one another in their complexity, with remember being less complex than understand; understand less complex than apply; in that order. However, because the revised taxonomy gives greater weight to textbook authors in the developing in-chapter and end-of-chapter questions, the requirement of a strict hierarchy has been relaxed to allow the categories to overlap one another, in such a way that a chemistry question classified under the category of understand (for instance, a question that require students to explain chemical concept), may be more complex a questions in the apply category, that require students to execute/perform a routine algorithm to arrive at the possible solution.

\section{Literature Review}

Recently, studies have been conducted to underscore the importance of the varying demand of questions assessed in examinations and in chemistry textbooks (Dávila \& Talanquer, 2010; Pappa \& Tsaparlis, 2011; Tikkanen \& Aksela, 2012; Gillette \& Sanger, 2014). This is because assessment could impact on students' future, especially in situations where students have to integrate and apply textual information into their personal experiences. 
Dávila and Talanquer (2010) conducted a study to investigate the nature of end-of-chapter questions and problems used in the United States. The findings from the research indicated that majority of the questions and problems included in the general chemistry textbooks were at the application and analysis levels of the original Taxonomy. The results further revealed that questions and problems at the application level were such that requires students or textbook users to use algorithms to arrive at the solutions. At the analysis level, questions were mostly to draw inference and make predictions, rather than, ask students to apply their understanding to hypotheses, create models and make valid and critical judgments.

Pappa and Tsaparlis (2011) evaluated forms of questions and the question-answer relationship in general chemistry textbooks using the case of intra- and intermolecular chemical bonding. The kind of knowledge tested by the questions was only declarative and procedural knowledge. None of the questions require students' metacognitive knowledge.

Tikkanen and Aksela (2012) adopted the framework of the revised Bloom's Taxonomy to analyze the kind of cognitive skills and knowledge measured by the Finnish chemistry matriculation examination questions. The research indicated that the questions were cognitively demanding, with majority $(77 \%)$ of the questions requiring higher order cognitive skills (HOCS). Though, the questions were not evenly distributed among analyze, evaluate and create categories of the cognitive process dimension. Gillette and Sanger (2014) analyzed the distribution of questions in the gas law chapters of secondary and introductory college chemistry textbooks from the US. The questions in these chapters were not significantly different based on the cognitive skill (lower order and higher order) measured by the questions. In other words, the distributions of questions in the gas chapters were homogenous for the cognitive skill across the textbooks.

Dávila and Talanquer (2010) classified and analyzed end-of-chapter questions and problems using a one-dimensional approach of the old Bloom's Taxonomy of cognitive objectives, but this study will use the two-dimensional framework of the revised Taxonomy to classify end-of-chapter questions. Tikkanen and Aksela (2012) study which is related to this research used the revised Bloom's Taxonomy to measure the dual perspective of learning and cognition in a summative assessment of matriculation examinations, but this study is designed to analyze end-of-chapter questions that prepare students in view of summative assessment. The studies of (Pappa \& Tsaparlis, 2011; Gillette \& Sanger, 2014) only analyzed distribution of questions in chemical bonding and gas laws chapters in some textbooks based on some forms of questions and variables among which are cognitive skills and knowledge dimension respectively.

From the literature reviewed, these studies reported that questions included in some chemistry textbooks were largely of the lower-order cognitive domain, and where there were comparatively few questions on HOCS; such were sparsely distributed among the categories of analyze, evaluate and create. If the current reform in science education with a strong advocacy for developing students' higher-order cognitive skills (HOCS) through question-asking, critical thinking, decision making and problem solving is an implied aim of science teaching, then the writing of textbooks, as well as the inclusion of in-chapter or end-of-chapter questions ought to tap into students' HOCS.

In the midst of the current reforms in science education, Nigeria as a nation has realized that science education is instrumental in achieving a developmental goal of becoming one of the developed economies of the world by 2020. Upon this realization, it became necessary to update existing science curricular to accommodate contemporary issues shaping and influencing the development of nations. The chemistry curriculum was revised for relevance and to enable students (even those who do not intend to proceed to higher education) become self-reliant and competent enough to meet global challenges. 
The chemistry curriculum operational in Nigeria was prepared in 2007 and made available for teachers use in 2009. The curriculum has completed 2-cycles of implementation at the senior school level. In preparing the science (chemistry) curricular, it was imperative that grounds are prepared for the translation of the documents into syllabi, textbooks and classroom processes. As a corollary, chemistry textbooks have also been revised to accommodate the reforms, and these textbooks ought to reflect the relevant issues by consolidating the text with questions or problems that aim to foster thinking process and problem solving among users, particularly, the students. This study, therefore, classify and analyze all the available end-of-chapter questions in selected chemistry textbooks based on two dimensional framework of the revised Bloom's taxonomy (see supplementary materials). This study was guided by a research question and a research hypothesis:

* What type of cognitive process skills and knowledge dimensions are measured by the endof-chapter questions in the chemistry textbooks used in Nigeria?

* There is no significant difference in the categories of the cognitive process skills measured among the three selected chemistry textbooks used in Nigeria.

\section{Nigerian Secondary School Education}

The senior secondary school education starts in senior school I and ends in senior school III. Chemistry is an elective subject, but all students who seek to make a career out of science-related courses, must offer chemistry as a compulsory subject in the senior secondary school. Chemistry textbooks, curriculum and syllabus are the main resources for the teaching and learning of chemistry in the senior school. Each chemistry teacher is given copies of the recommended textbooks and a copy of the curriculum to guide for scope and content of the topics to be taught. For the students, each one of them is given a copy of the textbook the teachers intend to use for the session. There are $4-5$ periods of chemistry instruction in a week for a class, and each period is 40 minutes long. There are three school terms in one academic year: September to December, January to April, May to August, and each term is about $12-13$ weeks long. By the end of the senior school education, students would have taken 120 hours of chemistry instruction. At the end of senior school III, students sit for public examinations, equivalent of Cambridge Local Examination Syndicate in the British system, for certification, university admission, training and employment. The national chemistry examinations are prepared by experienced chemistry teachers and university chemistry lecturers in conjunction with Examination Councils in Nigeria. The examiners use the syllabus, curriculum and textbooks as guides for preparing examination questions. The chemistry textbooks used in schools are written by international and Nigerian science educators within the broad guidelines of the national curriculum framework.

\section{Research Methodology}

The source of data for this study comprised 1750 questions drawn from three widely used chemistry textbooks among students and teachers in Nigeria. These chemistry textbooks were selected because they were approved for use in the senior school by the States' Ministries of Education. For ease of analysis, questions with multiple parts, each part of the questions were reviewed, classified, coded and separately analyzed.

This study is a quantitative research that employs content analysis to classify the end-of-chapter questions in the three selected chemistry textbooks used in Nigeria. The end-of-chapter questions were classified using the framework of the revised Bloom's Taxonomy that reflected a dual perspective of the cognitive process skills and the knowledge dimension. The revised Bloom's Taxonomy was used in this research because of its wider usage across the education communities to classify performance objectives, test items and questions (Anderson \& Krathwohl, 2001). For the 
cognitive process skills, the questions were also classified into LOCS and HOCS, since the six categories of revised taxonomy remember, understand, apply, analyse, evaluate and create can be arranged in a hierarchical structure, but not as rigid as the original Taxonomy.

To ensure the reliability of the classification of end-of-chapter questions, $10 \%$ of the questions were randomly selected and analyzed independently by one of the authors and a Professor of science education who have clear understanding of the revised Bloom's taxonomy and its application for classifying questions. The value of Kappa's measure of agreement was calculated based on the classification of the peer reviewers, for each of the cognitive process and the knowledge dimension. The Kappa-values for the cognitive process and knowledge dimensions were .91 and .94 respectively. The high values $(>.85)$ for the two dimensions of classification indicate a good measure of agreement between the two raters, which thus, guarantee a high reliability of the research.

\section{Results}

Table 2 presents the distribution of the 1750 questions drawn from the three selected chemistry textbooks according to the cognitive process skills of the revised Bloom's taxonomy. Only about $24 \%$ (421) of the questions asked in the three textbooks require higher order cognitive skills of (analyze, evaluate, and create). On the other hand, $76 \%$ of the questions were at the lower order cognitive level with the understand component taking about $41 \%$ of the questions, which arguably the category into which the largest number of the questions could be classified.

Table 2: Distribution of Questions in the Analyzed Chemistry Textbooks according to Cognitive Process Skills

\begin{tabular}{|c|c|c|c|c|c|c|c|c|c|c|c|c|c|c|}
\hline \multirow[t]{2}{*}{ Analyzed Textbooks } & \multicolumn{2}{|c|}{ Remember } & \multicolumn{2}{|c|}{ Understand } & \multicolumn{2}{|c|}{ Apply } & \multicolumn{2}{|c|}{ Analyze } & \multicolumn{2}{|c|}{ Evaluate } & \multicolumn{2}{|c|}{ Create } & \multicolumn{2}{|c|}{ Total } \\
\hline & Freq. & $\%$ & Freq. & $\%$ & Freq. & $\%$ & Freq. & $\%$ & Freq. & $\%$ & Freq. & $\%$ & Freq. & $\%$ \\
\hline Comprehensive & 111 & 27.19 & 169 & 41.3 & 32 & 7.8 & 85 & 20.8 & 3 & .7 & 9 & 2.2 & 409 & 23.4 \\
\hline \multicolumn{15}{|l|}{ Chemistry } \\
\hline Essential Chemistry & 241 & 28.5 & 330 & 39.0 & 95 & 11.2 & 147 & 17.4 & 13 & 1.5 & 21 & 2.5 & 847 & 48.4 \\
\hline New School & 83 & 16.8 & 219 & 44.3 & 49 & 9.9 & 110 & 22.3 & 22 & 4.5 & 11 & 2.2 & 494 & 28.2 \\
\hline \multicolumn{15}{|l|}{ Chemistry } \\
\hline Total & \multicolumn{2}{|c|}{435} & \multicolumn{2}{|c|}{718} & \multicolumn{2}{|c|}{176} & \multicolumn{2}{|c|}{342} & \multicolumn{2}{|c|}{38} & \multicolumn{2}{|c|}{41} & \multicolumn{2}{|c|}{1750} \\
\hline
\end{tabular}

Figure 1 shows the graphical representation and the quick summary of the distribution of the questions from the three selected chemistry textbooks into the categories of the cognitive process skills. The graph presented suggests that 'understand of the lower order cognitive skills has the highest number of the chemistry questions in each of the three textbooks, and this difference appears to be more pronounced in the Essential and New School Chemistry textbooks.

Comparable to understand category of the LOCS, is the analyze category in the higher order cognitive skills, HOCS. The graph further shows that analyze had the highest number of questions among the other categories of the HOCS (analyze, evaluate and create). 


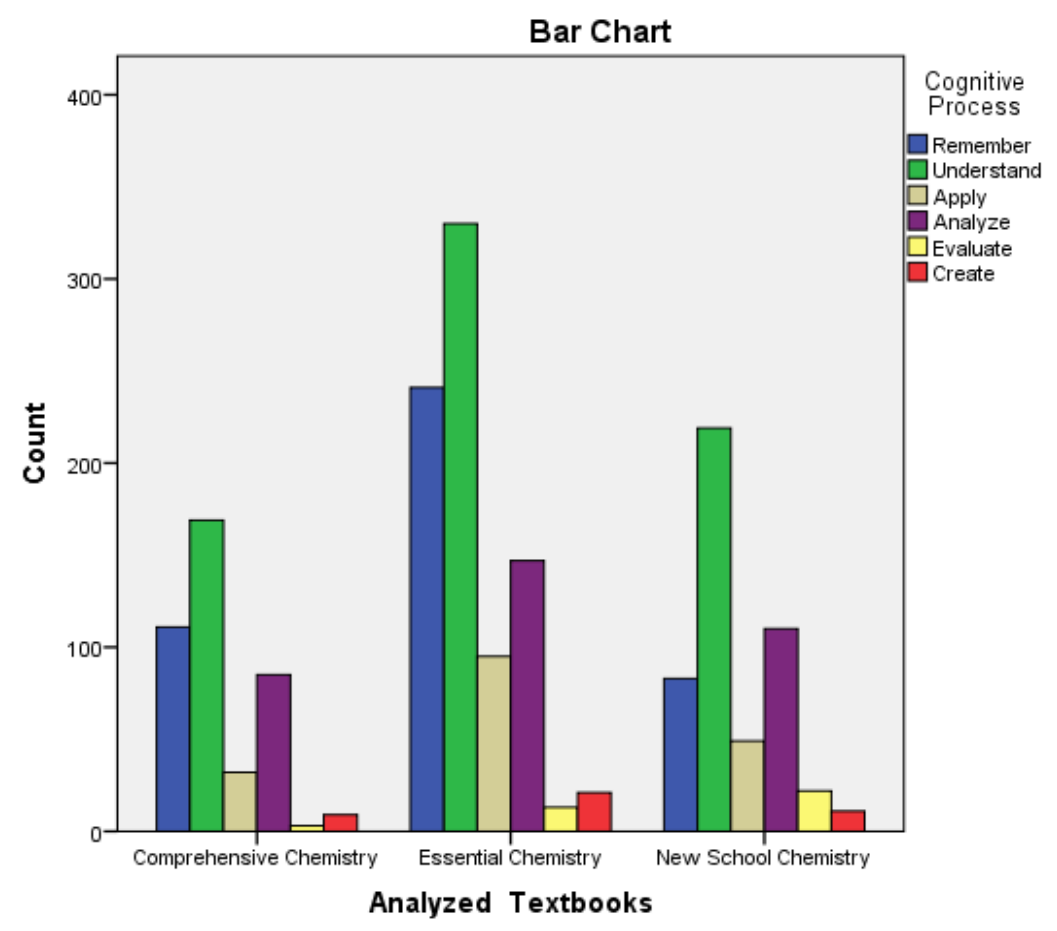

Figure 1. Frequency of Questions in the three Chemistry Textbooks according to Cognitive Process Skills

Table 3 presents the distribution of the questions obtained from the textbooks according to the knowledge dimension of the revised Bloom's taxonomy. It is shown that $46 \%$ of the textbooks' questions were designed to measure conceptual knowledge, while $32 \%$ and $22 \%$ of the questions could measure procedural and factual knowledge respectively.

Table 3: Distribution of Questions in the three Selected Chemistry Textbooks according to Knowledge Dimensions

\begin{tabular}{|c|c|c|c|c|c|c|c|c|}
\hline \multirow[t]{2}{*}{ Analyzed Textbooks } & \multicolumn{2}{|c|}{$\begin{array}{c}\text { Factual } \\
\text { knowledge }\end{array}$} & \multicolumn{2}{|c|}{$\begin{array}{l}\text { Conceptual } \\
\text { Knowledge }\end{array}$} & \multicolumn{2}{|c|}{$\begin{array}{l}\text { Procedural } \\
\text { Knowledge }\end{array}$} & \multicolumn{2}{|c|}{ Total } \\
\hline & Freq. & $\%$ & Freq. & $\%$ & Freq. & $\%$ & Freq. & $\%$ \\
\hline $\begin{array}{l}\text { Comprehensive } \\
\text { Chemistry }\end{array}$ & 72 & 17.6 & 181 & 44.3 & 156 & 38.1 & 409 & 23.4 \\
\hline Essential Chemistry & 223 & 26.3 & 390 & 46.0 & 234 & 27.6 & 847 & 48.4 \\
\hline New School Chemistry & 85 & 17.2 & 233 & 47.2 & 176 & 35.6 & 494 & 28.2 \\
\hline Total & \multicolumn{2}{|c|}{380} & \multicolumn{2}{|c|}{804} & & & \multicolumn{2}{|c|}{1750} \\
\hline
\end{tabular}

Figure 2 shows a graphical representation of the percentage distribution of the textbooks' questions in the three categories of the knowledge dimensions. The graph suggests that the conceptual knowledge has the highest number of questions in each of the three textbooks, followed by the procedural and factual knowledge. However, the number of questions designed to measure factual knowledge is more pronounced in the Essential chemistry textbook than in New School and Comprehensive chemistry textbooks. 


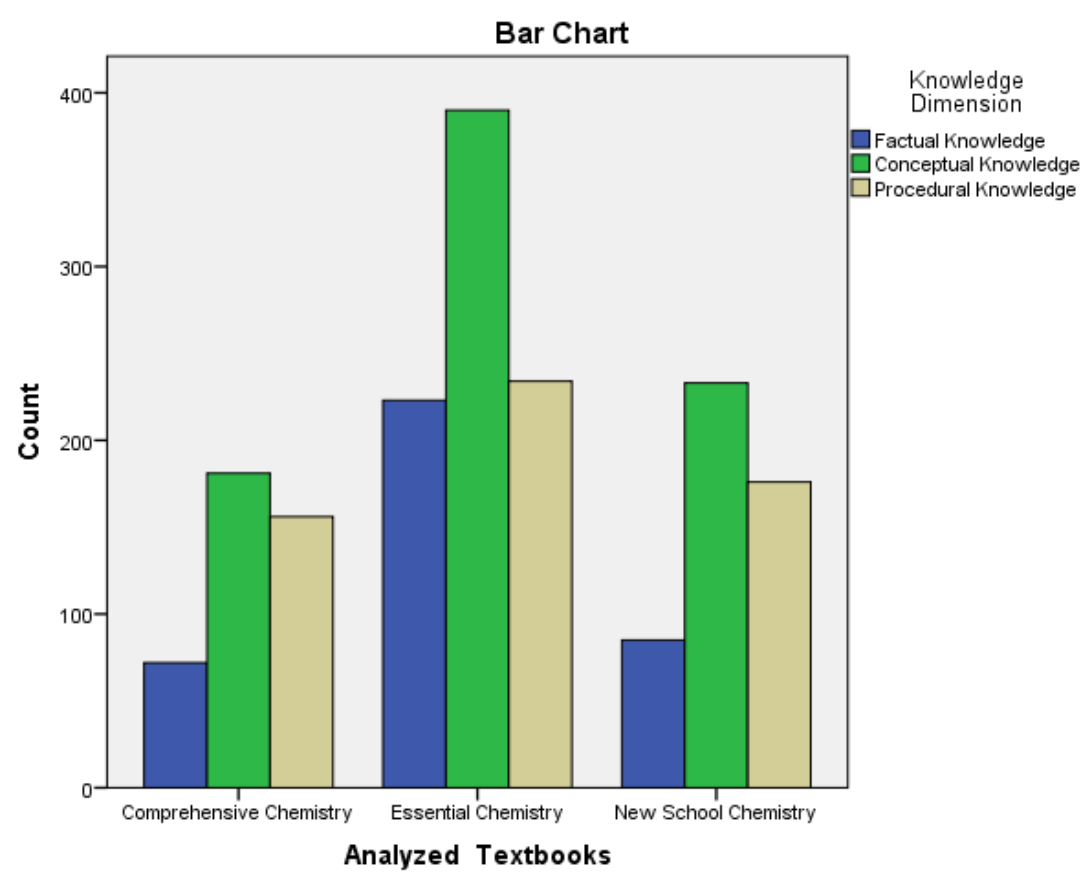

Figure 2. Frequency of Questions in the three Chemistry Textbooks according to Knowledge Dimension

Table 4 presents One-way between-groups Analysis of Covariance (ANCOVA) conducted to compare the cognitive process skills measured in the three selected chemistry textbooks. There was a statistically significant difference in the cognitive process skills measured by the selected textbooks $F$ $(5,1744)=5.61, \rho<.01$, partial eta squared $=.20$. Preliminary analyses were conducted to ensure that there was no violation of the assumptions of normality, linearity, homogeneity of variances and regression slopes, and reliable measurement of the covariates. The results of the Post hoc comparison using the Tukey HSD test indicated that the mean score of evaluate $(M=2.50, S D=.65)$ differs significantly from remember $(M=1.94, S D=.67)$, understand $(M=2.07, S D=.73)$, apply $(M=2.10, S D=$ $.67)$, analyze $(M=2.07, S D=.75)$. The mean scores of understand $(M=2.07, S D=.73)$ and remember $(M=$ $1.94, S D=.67$ ) also differs significantly.

Table 4: A One-way ANCOVA of the Cognitive Process Skills in the Selected Chemistry Textbooks

\begin{tabular}{lcccccc}
\hline $\begin{array}{l}\text { Analyzed } \\
\text { Textbooks }\end{array}$ & $\begin{array}{c}\text { Type III Sum of } \\
\text { Squares }\end{array}$ & Df & $\begin{array}{c}\text { Mean } \\
\text { Square }\end{array}$ & $\boldsymbol{F}$ & Sig. & $\begin{array}{c}\text { Partial Eta } \\
\text { Squared }\end{array}$ \\
\hline Cognitive & 14.22 & 5 & 2.85 & 5.61 & .00 & .20 \\
Error & 884.65 & 1744 & .51 & & & \\
Corrected Total & 898.87 & 1749 & & & & \\
\hline
\end{tabular}

\section{Discussion, Conclusion and Implications}

This study was designed to classify and to analyze whether or not, the end-of-chapter questions drawn from chemistry textbooks reflects a dual perspective on learning and cognition, and the advocacy of the current reform on the need to develop assessment methodologies that are HOCSoriented. The selected chemistry textbooks have wider usage among students and teachers in Nigeria, which was one of the major criteria for selecting the textbooks for categorization and subsequent analysis.

Table 2 presents the result of the cognitive process skills measured by the textbooks, where only about $24 \%$ of the end-of-chapter chemistry questions were of the higher order cognitive domain. The 
understand category recorded $41 \%$ of the remaining $76 \%$. These results slightly corroborate the findings of (Dávila \& Talanquer, 2010), who conducted a similar study and found that $64 \%$ of end-ofchapter questions in three introductory college chemistry textbooks were lower-order and $36 \%$ were high order. Though, majority of the end-of-chapter questions were application and analysis levels of the Bloom's cognitive categories. The authors argued that the questions were at the intermediate levels of cognitive demand, which they considered appropriate for a college level. Our classification shows that, majority of the questions included at the end-of-chapter in the selected chemistry textbooks for this study, were not as cognitively demanding as in the introductory chemistry college textbooks used in the US. This difference is due to the higher level of education for which the textbooks are prepared and used in the US. For the analyzed textbooks in this study, the authors realized that the understand category is a transfer-based educational objective that must first be emphasized in chemistry textbooks. For students to understand chemical concepts and for meaningful learning to take place, the new knowledge to be gained should have been connected to their prior knowledge (Ausubel, 1963).

The results further revealed that, the analyze sub-category of the cognitive process skills recorded $19.5 \%$ as the highest in the higher order cognitive domain across the textbooks. The textbook authors have also realized that it is educationally more defensible to consider analysis as an extension of understanding or as a prelude to evaluate and create-which were less emphasized in the end-ofchapter questions across the three textbooks.

Table 3 and figure 2 shows the percentage distribution and graphical representation of the subcategories of the knowledge dimension measured by the chemistry textbooks. About $46 \%$ of the endof-chapter questions require students to understand conceptual knowledge of chemical principles, theories and structures, while $32 \%$ of the questions require apply procedural knowledge of connecting conclusions with supporting statements; to distinguish relevant from extraneous materials in solving algorithmic questions; and to use appropriate procedures. These results are fairly consistent with the findings of (Tikkanen \& Aksela, 2012), which indicated a similar proportion of the questions that measured procedural knowledge, but differs significantly from the questions that measured conceptual knowledge. Though, these studies looked at questions for different assessment purposes (matriculation exams questions versus end-of-chapter questions in chemistry textbooks). Therefore, it becomes difficult to attribute these differences to one variable. However, these differences could be because summative assessment questions should be more cognitively demanding by measuring higher dimension of knowledge of students' cognition than end-of-chapter questions in textbooks.

The result of the ANCOVA in Table 4 compared the cognitive process skills measured by the three chemistry textbooks, and revealed a statistically significant difference in the number of questions that measure the six categories of the cognitive process skills (remember, understand, apply, analyze, evaluate and create) among the three textbooks $[F(5,1744)=5.61, \rho<.01]$. To identify which of the six categories of the cognitive process skills was the main contributor to the significant difference, we performed a Tukey HSD Post-hoc comparison and found that, what contributed to the significance is the number of end-of-chapter questions in the evaluate category which was the least emphasized, followed by the create category across the three textbooks. This findings is consistent with the results of (Dávila \& Talanquer, 2010), which indicated low percentages of questions and problems in the synthesis and evaluation categories in all the chapters analyzed in each textbooks. These similarities could be attributed to the less emphasis placed on the inclusion of end-of chapter questions that require students to apply what they have learnt in new context, make valid and critical judgment about chemical concepts, for instance, to validate conclusions that follow from the results of an experiment.

The statistical analyses arising from the classification of end-of-chapter questions in chemistry textbooks indicated that majority of the questions falls within the lower order cognitive domain in the 
order of understand, remember and apply. To compare the number of questions in the categories of the LOCS with the HOCS, understand and analyze were the categories that recorded the highest number of questions.

Our classification shows that the majority of the questions were at the conceptual knowledge level followed by the procedural knowledge. No single question in the three chemistry textbooks tested students' metacognitive knowledge as evident in knowledge dimensions presented in Table 1. This imply that the textbook authors did not make provision for questions that could aim at checking the extent to which students has acquired self-directed thinking in developing an action plan to solve problems.

The significant difference identified in the number of questions that were classified into the categories of the cognitive process skills further revealed the unequal distribution of questions among the categories across the three textbooks. This comparison was necessary to determine the contributor to the disproportionate distribution of questions among the categories, and to probably attempt to delineate what accounts for such distributions in the analyzed textbooks.

From the findings of this study, we could conclude that there were low percentage distribution of questions in evaluate and create categories, and this is liable to limit students' chances to develop meaningful understanding of chemical knowledge through questions or problems that taps into HOCS. The questions drawn from chemistry textbooks and analyzed in this study were predominantly of the LOCS-basic recall of memorized information or simply applying basic or memorized information to familiar situations, and/or applying algorithms to repetitive exercises. The dominance of such questions in chemistry textbooks has not justified the HOCS-promotion advocacy of the current reforms in assessment methodologies that necessitated chemistry curriculum revision and the subsequent review of chemistry textbooks in Nigeria.

The results of this study make it imperative to draw implications for textbook authors, teachers and students-who depend or rely on science textbook for instruction. It is important that textbook authors adopt a balance approach in the inclusion of end-of-chapter questions in their subsequent revision of the textual materials that reflects the categories of the cognitive process skills and the knowledge dimensions, if not equally, at least proportionately. This is because the majority of the questions were front-loaded in the lower-order cognitive domain, leaving comparative fewer questions to measure students higher order cognitive skills and no metacognitive question in the knowledge dimension. The end-of-chapter questions in the chemistry textbooks should be such that requires students to apply new knowledge in new contexts; generate hypotheses and design experiments to validate the hypotheses and make critical judgment about chemical phenomena.

Having established the end-of-chapter questions in chemistry textbooks were lopsided, it is equally important to alert the teachers of these discrepancies and the need for them to develop their own questions, such that will reflect the categories of the dual perspective of the revised Bloom's Taxonomy emphasized in this study, and not rely sole on textbook questions for testing.

Once the textbook authors and teachers start to feature questions that tap into students' higher-order cognitive skills, even though, there could be some initial resistance, the teachers should assist the students to actively construct knowledge in the teaching and learning of chemistry. The students could be engaged in team work, problem solving and decision making; as such activities enhance higher order cognitive skills. 


\section{References}

Ababio, O. Y. (2007). New school chemistry for senior secondary schools (2012 Edition). Nigeria: Africana First Publishers Limited.

Anderson, L. W. \& Krathwohl, D. R. (2001). A taxonomy for learning, teaching and assessing: A revision of Bloom's taxonomy of educational objectives. New York: Longman.

Ausubel, D. P. (1963). The psychology of meaningful verbal learning: An introduction to school learning. New York: Grune and Stratton.

Britton, B. K., Woodward, A. \& Binkley, M. (ed.), (1993). Learning from textbooks theory and practice. Hillsdale, NJ: Lawrence Erlbaum Associates.

Chambliss, M \& Calfee, R. (1998). Textbooks for learning: Nurturing children's minds. Oxford: Blackwell.

Cook, A. \& Tulip, D. (1992). The importance of selected textbook features to science teachers. Research in Science Teaching, 22, 91-100.

Dávila, K. \& Talanquer, V. (2010). Classification of end-of-chapter questions and problems in general chemistry textbooks used in the US. Journal of Chemical Education, 87, 97-101. Retrieved from http://www.chem.arizona.edu/tpp/JCE2009

Ezechukwu, E. (2010). Comprehensive chemistry for senior secondary school. Nigeria: Africana First Publishers Limited.

Gillette, G. \& Sanger, M. J. (2014). Analysing the distribution of questions in the gas law chapters of secondary and introductory college chemistry textbooks from the United States. Chemistry Education Research and Practice, 15, 787-799. Retrieved from http://pubs.rsc.org IDOI:10.1039/c4rp00115j

Odesina, I. A. (2009). Essential chemistry for senior secondary school. Nigeria: Africana First Publishers Limited.

Pappa, E. T. \& Tsaparlis, G. (2011). Evaluation of questions in general chemistry textbooks according to the form of the questions and the question-answer relationship (QAR): The case of intra- and intermolecular chemical bonding. Chemistry Education Research and Practice, 12, 262-270. Retrieved from http://pubs.rsc.org I DOI:10.1039/C1RP90031E

Spiegel, D. L. \& Wright, J. D. (1984). Biology teachers' preference in textbook characteristics. Journal of Reading, 27 (7), $624-628$.

Tikkanen, G. \& Aksela, M. (2012). Analysis of Finnish chemistry matriculation examinations questions according to cognitive complexity. Nordic Studies in Science Education, 8 (3), 258-268. Retrieved from https://www.journals.uio.no/index.php/nordina/article/viewFile/532/578 


\section{Supplementary Materials}

The classified and analyzed end-of-chapter questions were three selected chemistry textbooks commonly used in Nigeria. Table 5 presents the supplemental materials of the chapters analyzed, alongside labels assigned to each of the chapters for reference purposes. All the questions analyzed in each of the chapters were only essay questions. For questions with multiple parts, each part was taken as a single question that was coded, classified and analyzed.

Figures $3(\mathrm{a}-\mathrm{f})$ in the supplemental materials present the distribution of the questions according to the cognitive process and knowledge dimensions for each of the chapters analyzed in the New School, Comprehensive and Essential Chemistry Textbooks. The assigned labels correspond with the topics in Table 5. The graphs show differences and similarities in the end-of-chapter questions in each of the chapters and the selected chemistry textbooks.

Table 5: Chapters of Textbooks Analyzed and the Assigned Labels

\begin{tabular}{|c|c|c|c|}
\hline $\begin{array}{l}\text { Comprehensive Chemistry by } \\
\text { Mrs. Jumoke Ezechukwu }\end{array}$ & $\begin{array}{llll}\begin{array}{l}\text { Essential } \\
\text { Odesina }\end{array} & \text { Chemistry by } & \text { I.A } \\
\end{array}$ & $\begin{array}{l}\text { New School Chemistry by } \\
\text { Osei Yaw Ababio }\end{array}$ & Label \\
\hline Introduction To Chemistry & - & Introduction to Chemistry & IC \\
\hline $\begin{array}{l}\text { Nature of Matter and Separating } \\
\text { Techniques }\end{array}$ & $\begin{array}{l}\text { Nature Of Matter and Separation } \\
\text { Techniques }\end{array}$ & $\begin{array}{l}\text { Nature Of Matter and } \\
\text { Separation Techniques }\end{array}$ & MST \\
\hline Formulae and Valency & Symbols, Formulae and Equations & $\begin{array}{l}\text { Atoms, Moles, Formulae } \\
\text { and Equations }\end{array}$ & FV \\
\hline Particulate Nature Of Matter & Particulate Nature of Matter & - & PNM \\
\hline $\begin{array}{l}\text { Chemical Laws And Chemical } \\
\text { Combination }\end{array}$ & $\begin{array}{l}\text { Orbitals, Electronic Structure of } \\
\text { Atom and Chemical Combination }\end{array}$ & $\begin{array}{l}\text { Atomic Structure and } \\
\text { Chemical Combination }\end{array}$ & $\mathrm{CC}$ \\
\hline Kinetic Theory and State Of Matter & $\begin{array}{l}\text { Kinetic Theory of Matter and Gas } \\
\text { Laws }\end{array}$ & $\begin{array}{l}\text { Kinetic Theory of Matter } \\
\text { and Gas Laws }\end{array}$ & KT \\
\hline Acids, Bases and Salts & Acids, Bases and Salts & Acids, Bases and Salts & ABS \\
\hline Carbon and its Compounds & Carbon and its Compounds & Carbon and its Compounds & $\mathrm{C}$ \\
\hline $\begin{array}{l}\text { Hydrocarbons and Industrial } \\
\text { Chemistry }\end{array}$ & $\begin{array}{l}\text { Hydrocarbons, Crude Oil and } \\
\text { Industrial Chemistry }\end{array}$ & $\begin{array}{l}\text { Hydrocarbons, Crude Oil } \\
\text { and Industrial Chemistry }\end{array}$ & HIC \\
\hline $\begin{array}{l}\text { The Periodic Table and Periodicity } \\
\text { Of Properties of Elements }\end{array}$ & Periodic Table & $\begin{array}{l}\text { Periodic Table and Families } \\
\text { of Elements }\end{array}$ & PT \\
\hline $\begin{array}{l}\text { Electrical Nature of Chemical } \\
\text { Substances }\end{array}$ & Electrolysis & $\begin{array}{l}\text { Electrode Potentials, and } \\
\text { Electrolysis }\end{array}$ & $\mathrm{E}$ \\
\hline Types of Reaction & Oxidation and Reduction & $\begin{array}{l}\text { Types of Reaction, } \\
\text { Oxidation and Reduction }\end{array}$ & TR \\
\hline $\begin{array}{l}\text { Energy Changes in Chemical } \\
\text { Reactions }\end{array}$ & Energy and Chemical Reactions & $\begin{array}{l}\text { Energy and Chemical } \\
\text { Reactions }\end{array}$ & ECR \\
\hline Rates of Reaction & Chemical Reaction & Rates of Reaction & RR \\
\hline Air and Pollution & Air and Air Pollution & Air and Air Pollution & $\mathrm{AP}$ \\
\hline Water and Solution & Water, Solution and Solubility & $\begin{array}{lll}\text { Water, } & \text { Solution and } \\
\text { Solubility } & & \\
\end{array}$ & WS \\
\hline Hydrogen & Hydrogen and its Compounds & Hydrogen and Hydrides & $\mathrm{H}$ \\
\hline Oxygen and its Compounds & Oxygen and its Compounds & Oxygen and its Compounds & $\mathrm{O}$ \\
\hline Sulphur and its Compounds & Sulphur and its Compounds & Sulphur and its Compounds & $S$ \\
\hline Halogens and their Compounds & The Halogens & The Halogen Family & $\mathrm{HF}$ \\
\hline Nitrogen and its Compounds & Nitrogen and its Compounds & $\begin{array}{l}\text { Nitrogen and } \\
\text { Compounds }\end{array}$ & $\mathrm{N}$ \\
\hline Introduction to Organic Chemistry & Organic Chemistry (I) & Organic Chemistry (I) & $\mathrm{OC}(\mathrm{I})$ \\
\hline $\begin{array}{l}\text { Alkanols, Alkanoic, Alkanoates, } \\
\text { Carbohydrates and Giant } \\
\text { Molecules }\end{array}$ & Organic Chemistry (II) & Organic Chemistry (II) & $\begin{array}{l}\text { OC } \\
\text { (II) }\end{array}$ \\
\hline Metals and their Compounds & Metals and Their Compounds (I) & Metals & $\mathrm{MC}$ \\
\hline
\end{tabular}




\begin{tabular}{llllc}
\hline & & \multicolumn{2}{l}{ Compounds (I) } & \\
\hline Transition Metals & Metals and Their Compounds(II) & $\begin{array}{l}\text { Metals and } \\
\text { Compounds (II) }\end{array}$ & their TM \\
\hline Radioactivity & Nuclear Chemistry & $\begin{array}{l}\text { Radioactivity and Nuclear } \\
\text { Chemistry }\end{array}$ & R \\
& - & Mass Volume Relationships in & $\begin{array}{l}\text { Volumetric and Qualitative } \\
\text { Analysis }\end{array}$ & V \\
\hline- & Reaction & Chemical Equilibrium & CE \\
\hline
\end{tabular}

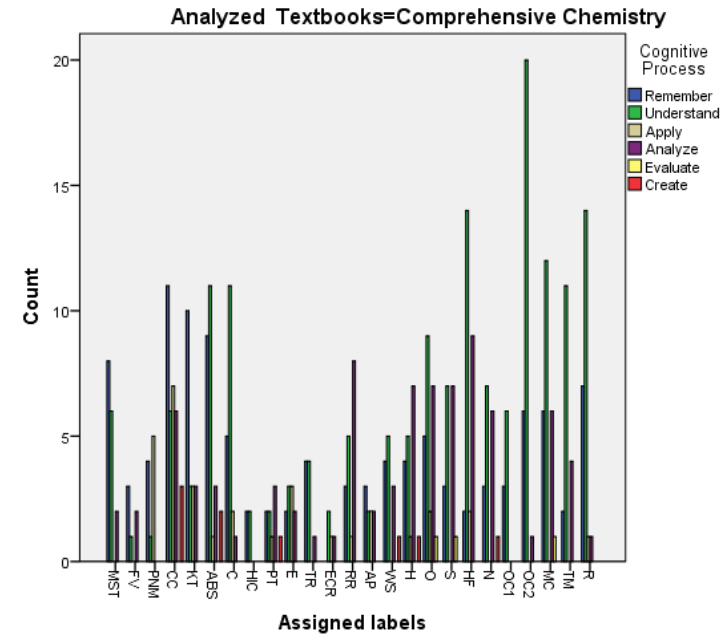

(a) Comprehensive chemistry Textbook

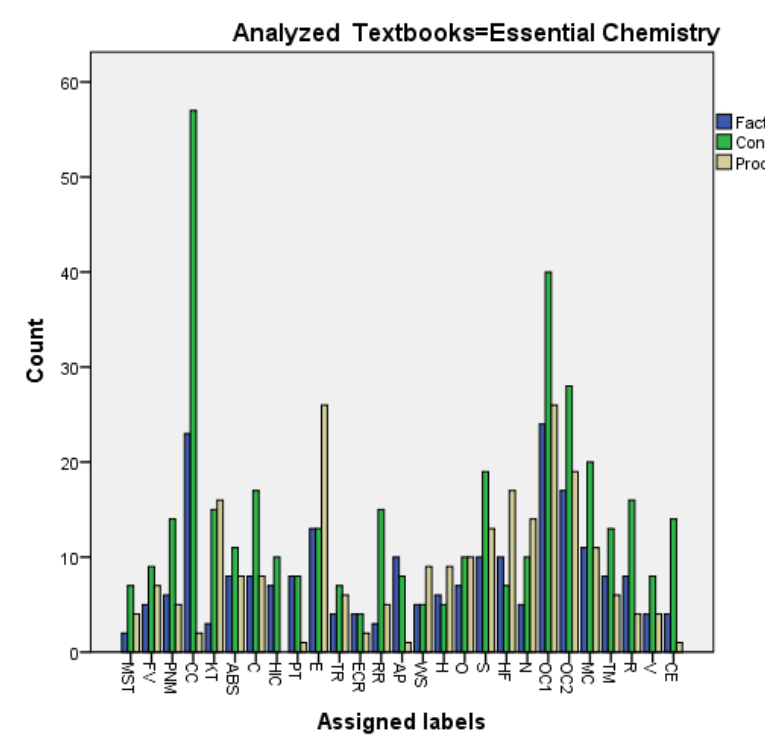

(c) New School Chemistry Textbook

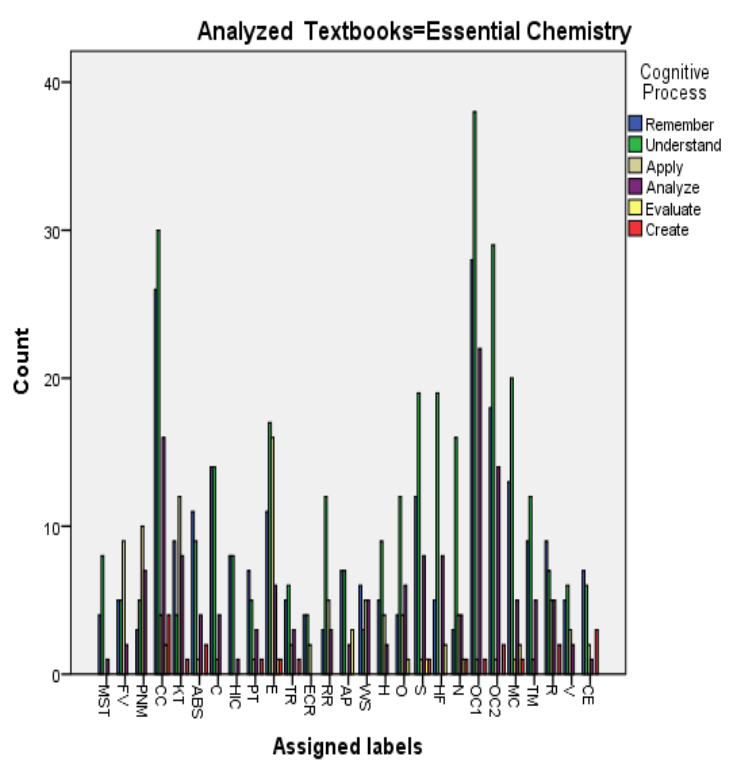

(b) Essential Chemistry Textbook

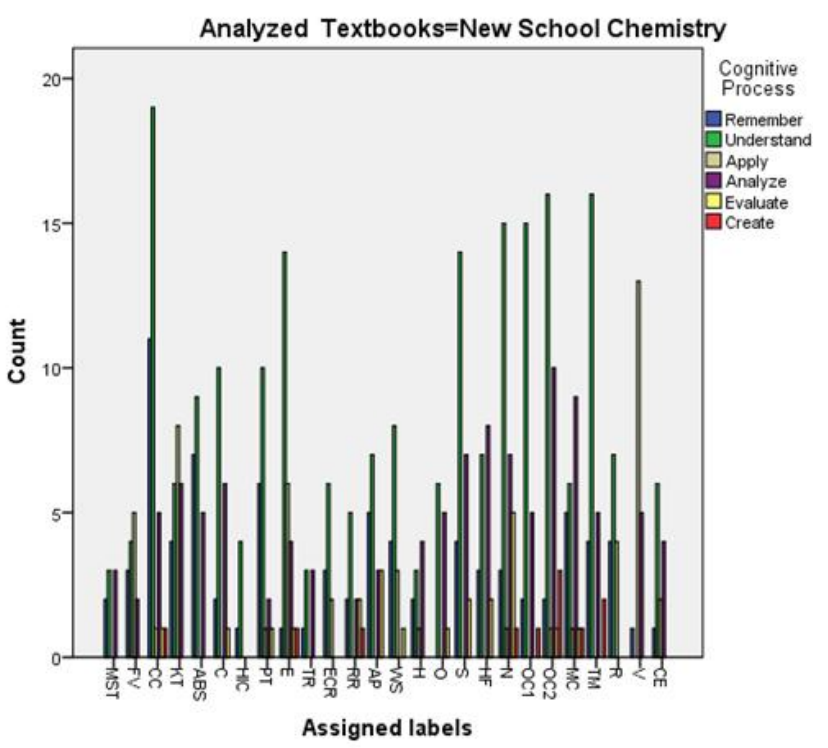

(d) Essential Chemistry Textbook 


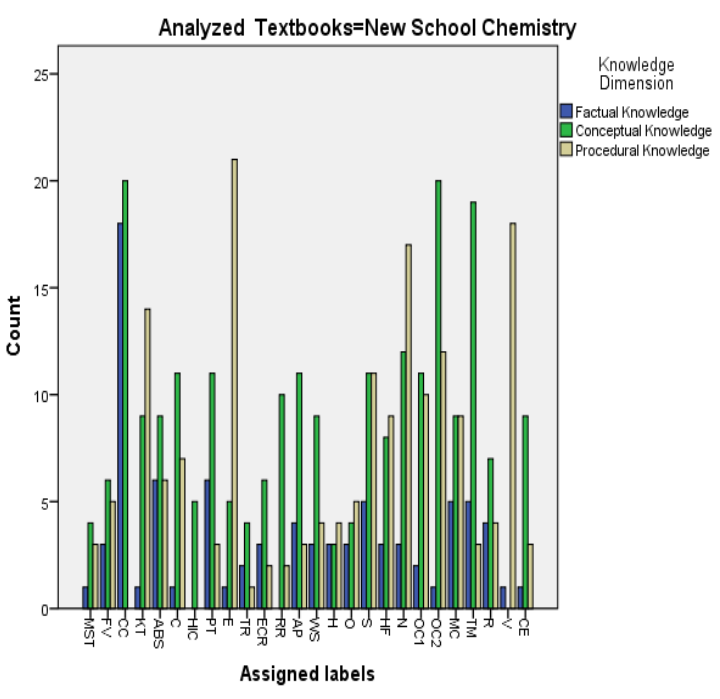

(e) Comprehensive Chemistry Textbook

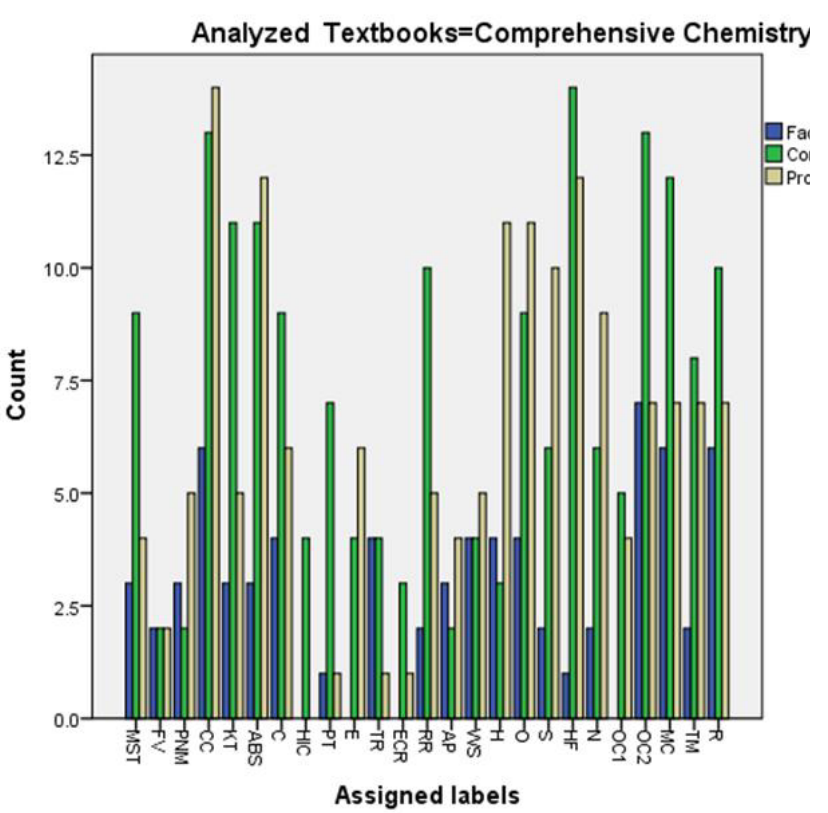

(f) New School Chemistry Textbook

Figure 3 (a-f). Classification of questions in the categories of the cognitive process skills and the knowledge dimensions for each of the analyzed chapters of Comprehensive, Essential and New school chemistry textbooks. The assigned labels correspond to each of the chapters presented in Table 4 of the supplementary materials. 